\title{
21
}

\section{Physical Model Study, CSO Diversion through Bottom Outlet Slot, Site DS-4 Upper Rouge Tunnel System}

\author{
James W. Lewis, Steven J. Wright, James Sherrill, and \\ Mark Pribak
}

The objective of this study was to determine the discharge characteristics of flow through a longitudinal bottom discharge slot in a nearly horizontal circular pipe. The study consisted of an experimental model constructed in the University of Michigan Hydraulics Laboratory. The model study was a scaled representation of a proposed bottom outlet slot diversion structure for the Upper Rouge Tunnel (site DS-4) combined sewer overflow project in Southeast Michigan. The purpose of the slot is to allow discharge from the flow conduit into a deeper storage facility until the storage facility becomes filled to capacity after which the flow would continue to overflow in the original conduit. The main goals of the bottom outlet slot design are to control the flow passively and to minimize head losses in the conduit to avoid excessive backwater effects from the diversion structure. Experiments were performed in a scale model of a proposed design for the discharge structure. One important observation in describing the flow was that the flow passed through critical depth near the upstream end of the slot and was supercritical above the slot. Further, the flow patterns above the slot were clearly not two-dimensional and considerable flow variations were noticed in the lateral direction. The experimental results showed that increasing the pipe slope causes only minor increases to the required slot length. A

Lewis, J., S.J. Wright, J.D. Sherrill and M. Pribak. 2009. "Physical Model Study, CSO Diversion through Bottom Outlet Slot, Site DS-4 Upper Rouge Tunnel System." Journal of Water Management Modeling R235-21. doi: 10.14796/JWMM.R235-21.

(C) CHI 2009 www.chijournal.org ISSN: 2292-6062 (Formerly in Conceptual Modeling of Urban Water Systems. ISBN: 978-0-9808853-2-3) 
consistent relationship is observed between the discharge divided by slot width and the required slot length to pass that flow. A simple methodology for developing a relation for the slot length required to intercept a specified discharge is proposed and compared to the experimental data.

\subsection{Introduction}

A longitudinal outlet slot constructed in the bottom of the existing DS-4 outfall conduit is proposed as a diversion structure conveying flow from the combined sanitary collection system to the Upper Rouge Tunnel during periods of high system discharge. Figures 21.1 and 21.2 present a preliminary version of the proposed design. The purpose of this slot is to allow flow to pass through the slot into the Upper Rouge Tunnel when the tunnel is not full and to pass flow downstream with minimal head loss once the tunnel has filled. The design flow for this site is $33.9 \mathrm{~m}^{3} / \mathrm{s}$ and the goal for this study was to determine acceptable bottom outlet slot geometries such that $100 \%$ of the design flow would be diverted through the slot whenever the storage tunnel is not full.

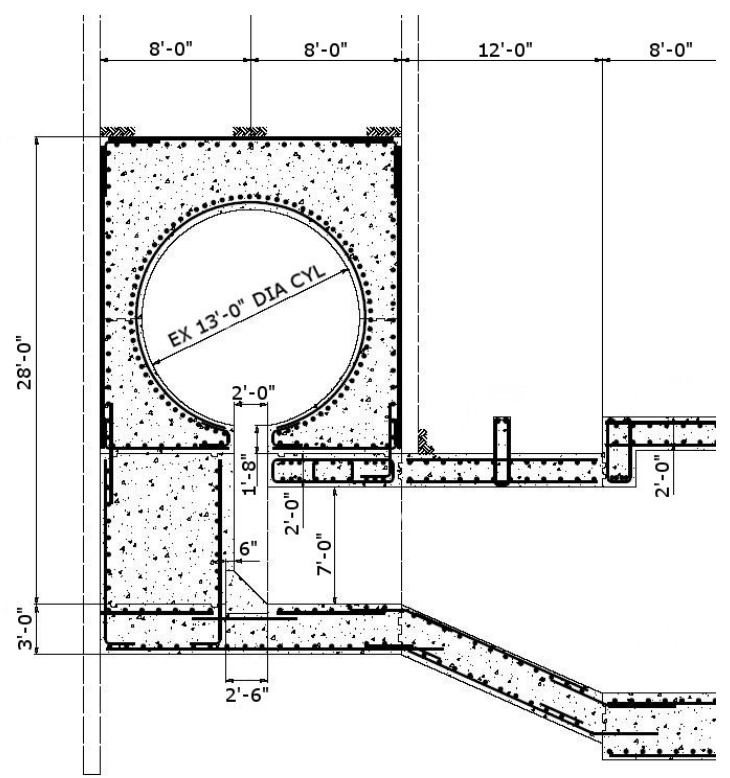

Figure 21.1 Section view of proposed bottom outlet slot design at site DS-4 (provided by Wade Trim). 


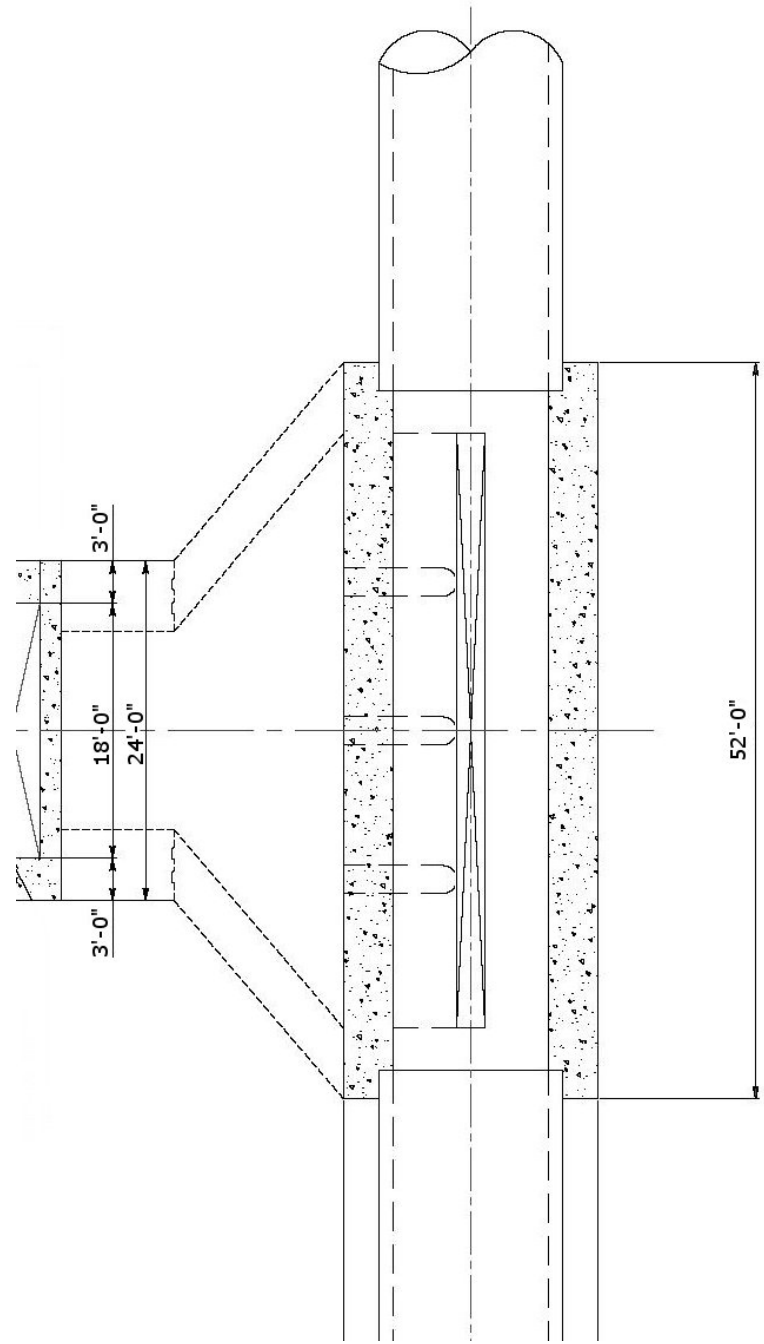

Figure 21.2 Plan view of proposed bottom outlet slot design at Site DS-4 (provided by Wade-Trim).

There are two main advantages for using a bottom outlet slot design as a diversion structure. First of all, the flow control is completely passive. There are no gates or control switches required to divert flow back to the conduit when the tunnel is full. Furthermore, this bottom outlet slot design 
minimizes the amount of hydraulic energy loss experienced in the system. With no obstructions protruding into the flow cross section, a minimal amount of resistance will occur as flow passes over a full tunnel.

The complex shape of the water surface as it flows out the bottom slot may require a fully $3-\mathrm{D}$ model to accurately predict the outcome. A simplified 2-D numerical model is proposed and compared with the physical model study results. Previous work by Warrick and Yitayew (1988), and Fischer, et al. (1979) discusses outflow orifice systems and side wall weirs using the conservation of energy principle. However, there seems to be no information about flow through slot openings extending along the bottom of the pipe in the longitudinal direction.

\subsection{Physical Model Study}

\subsubsection{Experimental Setup}

A scale model was constructed in the University of Michigan Hydraulics Laboratory in order to determine an appropriate slot length to pass the design flow through the Upper Rouge Tunnel DS-4 bottom outlet slot system. The diameter of the designed prototype system was $3.96 \mathrm{~m}$ and the experimental model used a $20.3 \mathrm{~cm}$ diameter (I.D.) pipe, thus making the physical scale ratio $1: 19.5$. Considering dynamic similarity based on the Froude number, the model discharge should be a factor of $(19.5)^{-2.5}$ of the prototype flow (Henderson, 1966). The prototype design flow of the DS-4 site is $33.9 \mathrm{~m}^{3} / \mathrm{s}$, which corresponds to $20.3 \mathrm{~L} / \mathrm{s}$ in the model. At the design discharge, the approach flow in the pipe will have a Reynolds Number in excess of 100,000 , a level generally accepted as sufficiently large to avoid significant scale effects. The discharge was measured in the laboratory using a master venturi meter.

An illustration of the experimental setup is presented in Figure 21.3. The source of flow came from a constant head reservoir tank and was controlled by a $20.3 \mathrm{~cm}$ gate valve. Approximately $5 \mathrm{~m}$ of $20.3 \mathrm{~cm}$ PVC pipe was placed upstream of the $1.52 \mathrm{~m}$ clear acrylic pipe section containing the bottom outlet slot. A wire basket filled with coarse crushed limestone was placed at the start of the straight length of PVC pipe to eliminate any secondary flows from the upstream bends. The downstream end of the acrylic pipe was open such that any continuing flow freely exited out the end. 


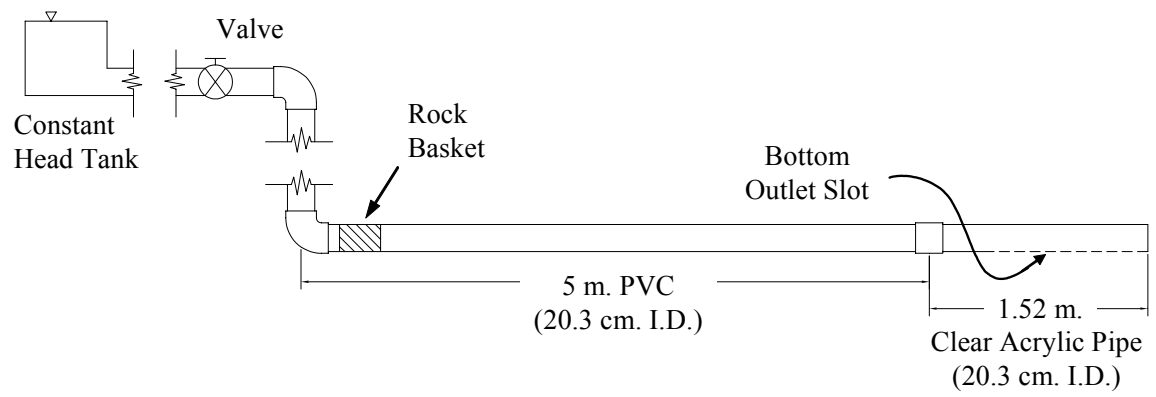

Figure 21.3 Experimental setup.

The slot was constructed by mounting the acrylic pipe on a mill bed and machining the slot to the desired dimensions. The slot walls were thus vertical as opposed to aligned with the pipe radius.

Initially, the model construction included the vertical walls (as shown in Figure 21.4; here the camera was not quite horizontal) below the slot opening with the dimensions provided in preliminary design drawings that were provided by Wade Trim (Figures 21.1 and 21.2 above). Preliminary experiments were performed with these walls in place and with a free discharge (walls removed) to determine whether either the slot length or the upstream water depth was influenced by their presence. It was concluded that these walls do not influence the slot discharge in any way that modifies either the upstream depth in the conduit or the length of slot filled by a particular flow. Following this determination, the remaining measurements were conducted with the freely discharging slot since this configuration allowed for better observations of the nature of the flow.

The slot width in the preliminary design was $61.0 \mathrm{~cm}$, corresponding to a $3.12 \mathrm{~cm}$ slot width for the model. The initial slot length of the model was $81.4 \mathrm{~cm}$ (15.8 $\mathrm{m}$ prototype) based on preliminary measurements that were made in a much smaller diameter pipe. When it became clear that the slot was unable to pass the design discharge, the slot length was increased to $108 \mathrm{~cm}$ (21.1 m prototype). Following experiments with this slot, the slot width was increased to $3.89 \mathrm{~cm}$ (76.2 $\mathrm{cm}$ prototype). The pipe was supported along the top of a laboratory flume with adjustable slope capability. The pipe slope could be altered using the flume slope adjustment mechanism. Measurements were taken at slopes of 0 and 0.008 . 


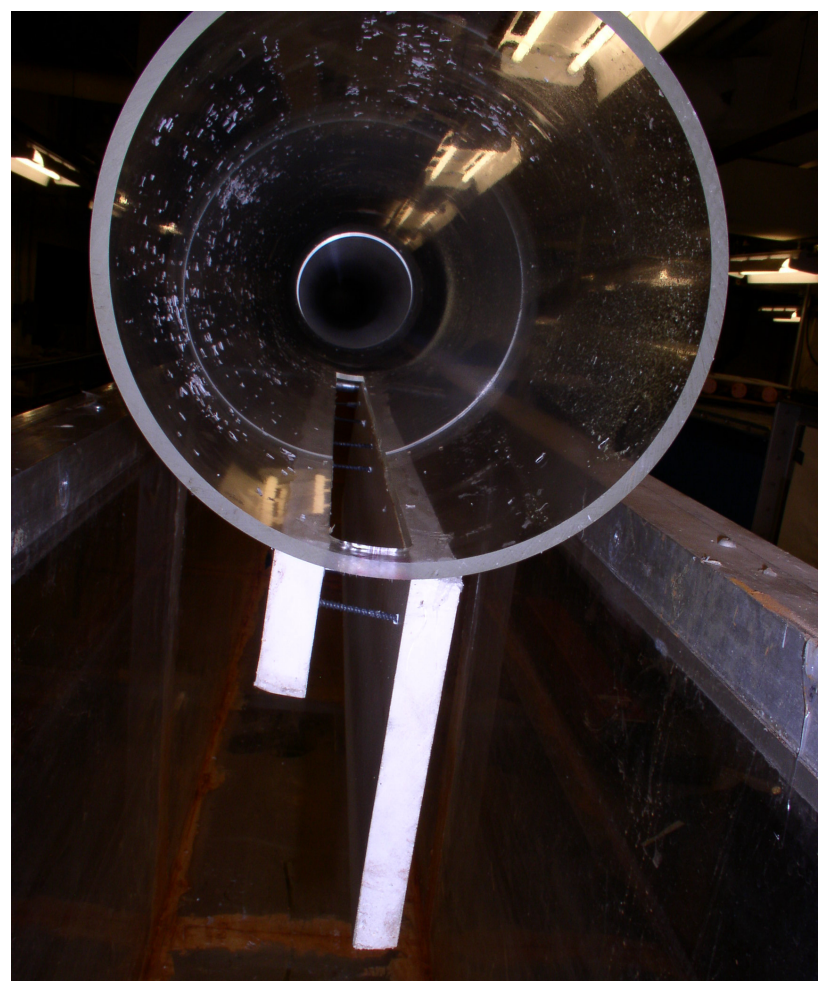

Figure 21.4 Side walls below slot.

\subsubsection{Experimental Procedure}

Once the experimental model was prepared, the procedure was straightforward. The only variables which changed for each slot width were the model slope and discharge. As the discharge was changed, the slot length required to accommodate such a flow also changed. Starting with an initially closed valve, it was opened incrementally until the flow could no longer fully pass through the slot. For each valve opening, the venturi meter reading was recorded as well as the filled slot length distance. Defining this distance of flow at the downstream end required careful interpretation. The slot length for this study has been defined as the complete distance covered by the flow, including the distance after which the center profile drops below the invert of the pipe. In other words, there was a portion of the downstream water 
surface profile which experienced flow only along the side edges of the slot and this distance was included in the definition of the required slot length.

\subsection{Experimental Results}

Several initial observations were made concerning the characteristics of the flow. The trajectory of water leaving the bottom outlet slot was very similar at both ends of the opening. Although the flow is more complex than that, this observation is indicates that the horizontal velocity in the flow is fairly consistent in the pipe above the slot. Since the depth is continuously decreasing along the slot, this observation would also imply that the Froude number of the flow increases along the slot length. To verify this behavior, a small obstacle was placed in the flow above the slot to determine whether a hydraulic jump would form locally upstream of the obstacle. The hydraulic jump would indicate a transition between a supercritical flow and the subcritical flow caused by the obstacle. By moving the obstacle further upstream, it was observed that the flow passes from a subcritical state upstream of the slot to a supercritical state over the slot with the transition through critical flow depth occurring approximately at the upstream end of the slot. A photograph of the flow profile can be seen in Figure 21.5.

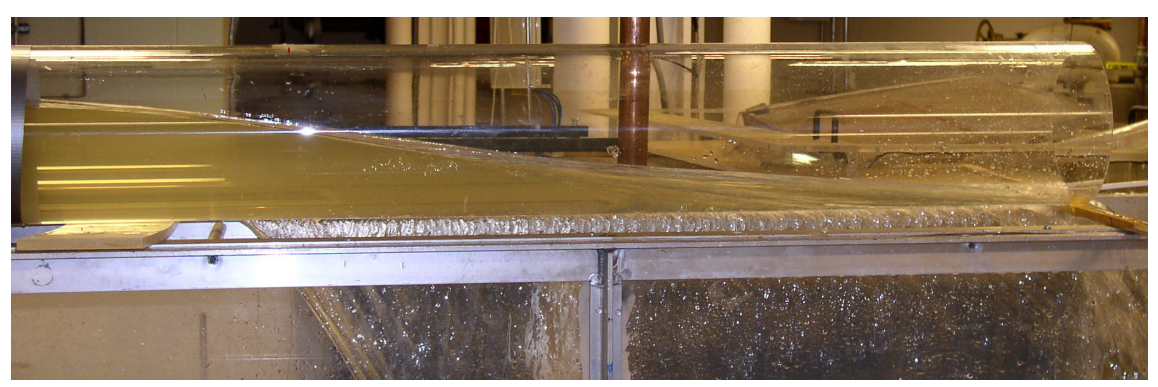

Figure 21.5 Photograph of flow profile.

Visual observations clearly indicate that the flow in the conduit is not two-dimensional above the slot and varies considerably in the lateral direction, especially as the water depth approaches zero. At the upstream end of the slot the flow is fairly uniform laterally but this is not the case towards the downstream end of the slot flow. A very weak hydraulic jump developed immediately above the slot causing a small increase in depth above the slot 
compared to the flow on either side of the slot. Moving further downstream, eventually the exiting flow begins to influence the profile so that a depression in the water surface above the slot develops. This depression becomes so great that the water surface is below the pipe invert in the center of the slot, even where there is a fair amount of flow still remaining in the pipe. As the flow depth feathers out to approach zero, the center of the slot appears to be open to the atmosphere with flow still occurring near the edges of the slot. This flow persists for some distance downstream (typically about $10 \mathrm{~cm}$ at the laboratory scale) and it is believed that this effect would be accentuated by surface tension as a very thin film flow develops. Assuming the effect is due to surface tension, this effect is not reproduced properly in the smaller scale model and the film flow will be exaggerated compared to what would be expected in the prototype. In the results reported below, the slot is considered effective in capturing the flow when all but a small portion of the film flow exits through the slot. Measurements of the rate of water passing downstream of the slot, for a flow condition where the full length of the slot was deemed effective in passing the required discharge, indicate that this bypassing flow would be on the order of $0.1 \mathrm{~m}^{3} / \mathrm{s}$ prototype, or less than one percent of the design flow. It is believed that this bypassing will not occur at the prototype scale.

Experimental results are presented in Figures 21.6 through 21.9 and the raw data are provided in Table 21.1.

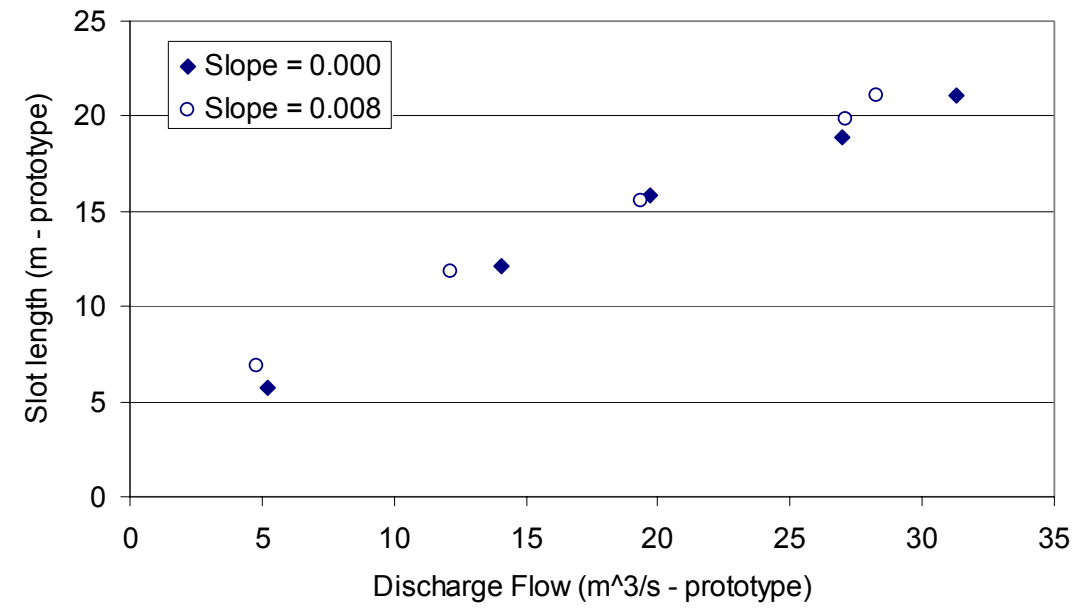

Figure 21.6 Slot width $=61.0 \mathrm{~cm}$ (prototype). 


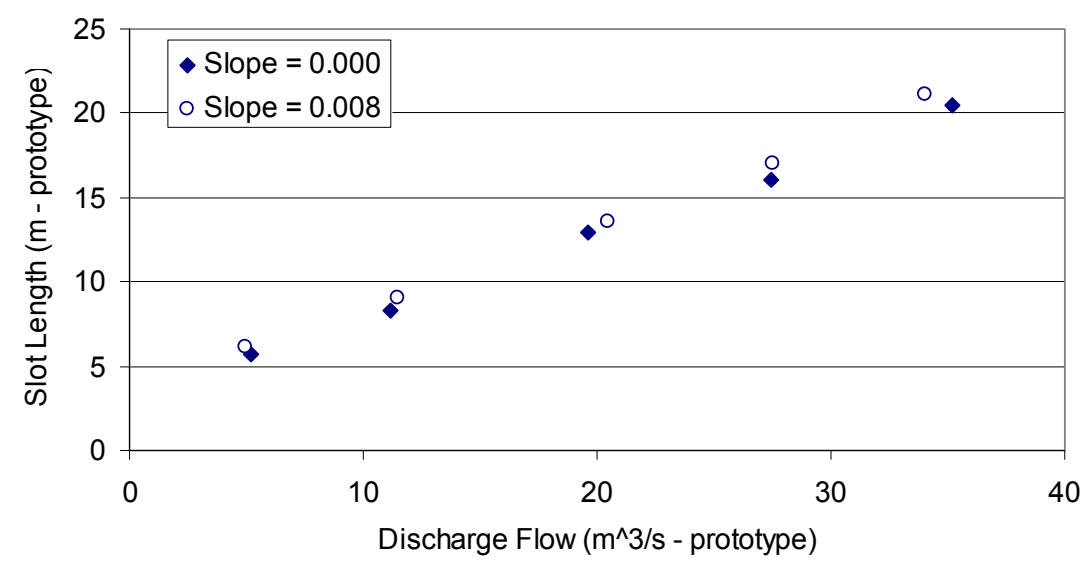

Figure 21.7 Slot width $=76.2 \mathrm{~cm}$ (prototype).

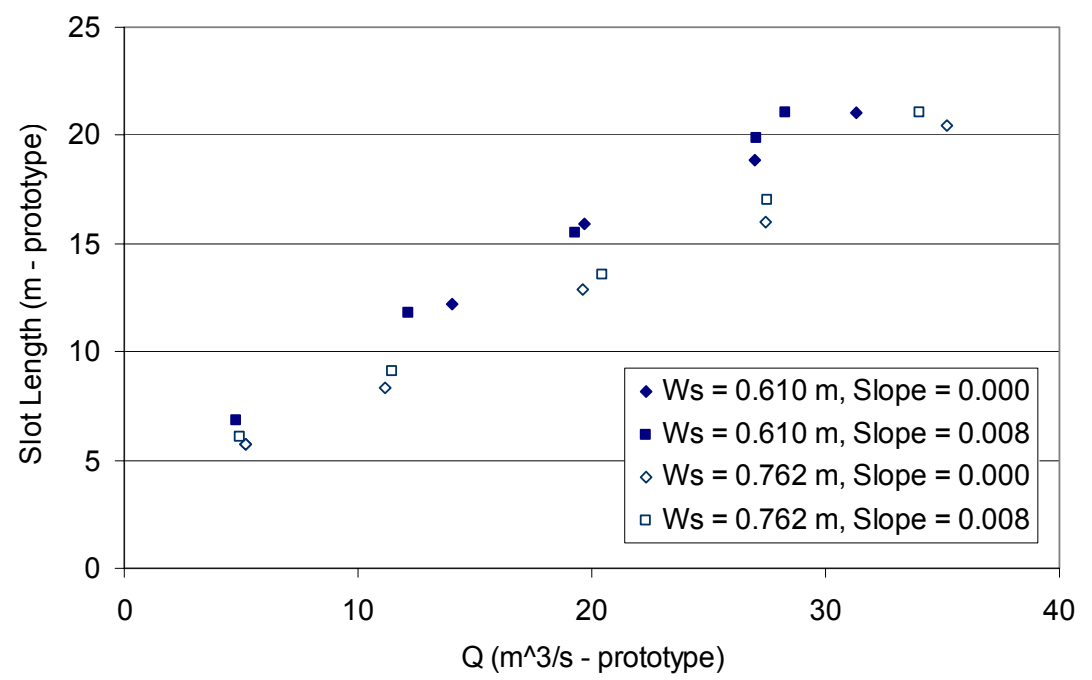

Figure 21.8 All experimental data (Ws is the slot width, prototype). 


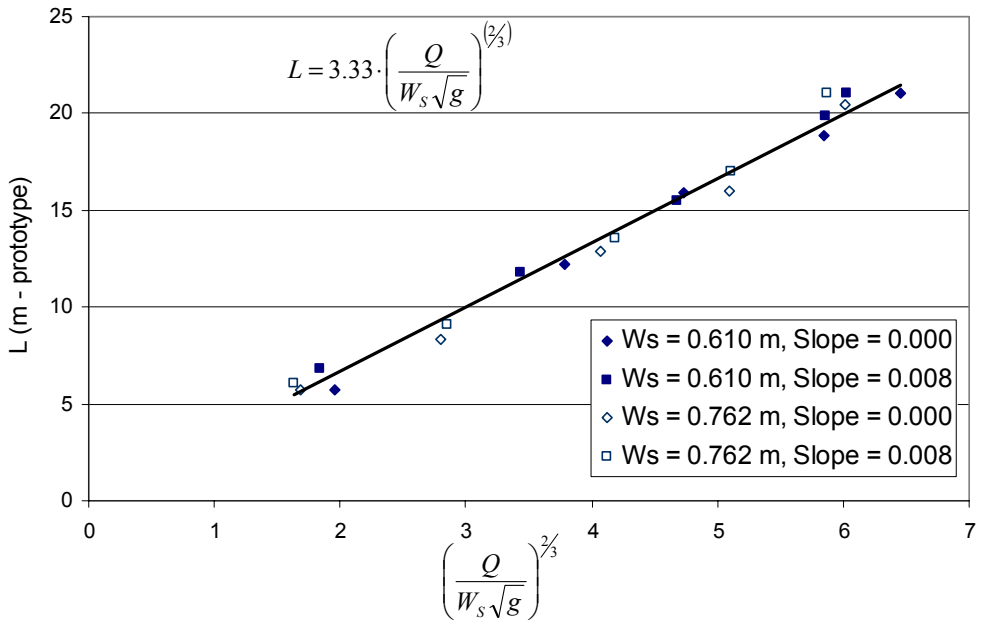

Figure 21.9 Dimensional analysis $\left(\mathrm{Q} /\left(\mathrm{W}_{\mathrm{s}} \sqrt{ } \mathrm{g}\right)\right)^{2 / 3}$ vs. $\mathrm{L}\left(\mathrm{W}_{\mathrm{s}}\right.$ is the slot width, prototype).

Table 21.1 Experimental data.

\begin{tabular}{cccc}
\hline Slot Width $(\mathrm{cm})$ & Slope & Slot Length Req'd. $(\mathrm{m})$ & $\mathrm{Q}\left(\mathrm{m}^{3} / \mathrm{s}\right)$ \\
\hline 61.0 & 0.000 & 5.73 & 5.21 \\
61.0 & 0.000 & 12.17 & 14.06 \\
61.0 & 0.000 & 15.88 & 19.70 \\
61.0 & 0.000 & 18.85 & 26.98 \\
61.0 & 0.000 & 21.08 & 31.32 \\
61.0 & 0.008 & 6.841 & 4.772 \\
61.0 & 0.008 & 11.794 & 12.169 \\
61.0 & 0.008 & 15.509 & 19.328 \\
61.0 & 0.008 & 19.843 & 27.075 \\
61.0 & 0.008 & 21.081 & 28.258 \\
76.2 & 0.000 & 5.727 & 5.207 \\
76.2 & 0.000 & 8.327 & 11.167 \\
76.2 & 0.000 & 12.909 & 19.641 \\
76.2 & 0.000 & 16.004 & 27.444 \\
76.2 & 0.000 & 20.462 & 35.200 \\
76.2 & 0.008 & 6.098 & 4.993 \\
76.2 & 0.008 & 9.070 & 11.476 \\
76.2 & 0.008 & 13.528 & 20.495 \\
76.2 & 0.008 & 16.995 & 27.536 \\
76.2 & 0.008 & 21.081 & 34.014 \\
\hline
\end{tabular}


For a given discharge, a greater pipe slope required a minimally longer slot length. Varying the slope from slightly adverse to a maximum of 0.008 resulted in a very minor increase in the slot length. The more significant behavior was that as the slot width increased the required slot length decreased, as seen by the presentation of the data in Figure 21.8. Using dimensional analysis reasoning to combine variables, an equation was determined that fits the data well:

$$
L=3.33 \cdot\left(\frac{Q}{W_{S} \sqrt{g}}\right)^{(2 / 3)}
$$

where:

$$
\begin{aligned}
L & =\text { slot length required }, \\
W_{S} & =\text { slot width, } \\
Q & =\text { discharge, and } \\
g & =\text { gravitational acceleration. }
\end{aligned}
$$

Equation 21.1 is dimensionally homogeneous and was developed to apply for prototype conditions with any consistent units. Figure 21.9 above indicates the slot length required as a function of discharge, slot width, and gravity. This plot shows that the data points form a consistent relationship according to the equation above within the range of flows that were considered.

\subsection{Numerical Modeling}

Visual observations indicated a complex 3-dimensional water surface profile above the bottom outlet slot opening. The changes in depth in the lateral direction were especially noticeable as the depth approached zero. A twodimensional approximation is formulated here which is similar to an orificediffuser calculation (Fischer, et al. 1979, Wu and Gitlin 1975). The proposed method marches discretely from the upstream end of the slot to the point where the depth is predicted to be zero. From visual observations in the experiments the initial condition in the analysis is the upstream condition that the flow is slightly supercritical right at the start of the slot (as discussed in 21.3). A root-finding method is used to calculate this critical depth for a given discharge flowing in a circular cross-section. The equations used to solve this system are the conservation of mass, the conservation of energy, and the orifice equations applied over a discrete length of the conduit. 
conservation of mass:

$$
A_{i+1} v_{x, i+1}=A_{i} v_{x, i}-C_{D} W_{s} v_{y, i} \Delta x
$$

conservation of energy:

$$
h_{i}+\frac{\left(v_{x, i}^{2}\right)}{2 g}-\frac{C_{f} \cdot P_{i} \cdot \Delta x}{g \cdot A_{i}} v_{x, i}^{2}+S \cdot \Delta x=h_{i+1}+\frac{\left(v_{x, i+1}^{2}\right)}{2 g}
$$

orifice equation:

$$
v_{y, i}=\sqrt{2 g h_{i}}
$$

where:

$$
\begin{aligned}
v_{\mathrm{x}, \mathrm{i}} & =\text { velocity in } x \text { direction at step } x_{i}, \\
v_{\mathrm{y}, \mathrm{i}} & =\text { velocity in } y \text { direction (slot discharge) at step } x_{i}, \\
h_{i} & =\text { the height of water at step } x_{i}, \\
g & =\text { gravitational acceleration, } \\
A_{i} & =\text { cross-sectional area at step } x_{i}, \\
P_{i} & =\text { wetted perimeter at step } x_{i} \\
W_{S} & =\text { width of slot, } \\
C_{D} & =\text { Coefficient of discharge through bottom slot, } \\
C_{f} & =\text { Friction coefficient } \\
S & =\text { slope, and } \\
\Delta x & =\text { step size. }
\end{aligned}
$$

The third term in the energy equation represents the friction loss and was neglected for this application because the slot length is a relatively short distance. The first five data points in Table 21.1 (slope $=0.000$ and slot width $=61 \mathrm{~cm}$ ) were used to calibrate the value for the discharge coefficient. The equations were solved using a root-finding procedure for the system of equations to find $h$ and $v$ at each discrete step.

The calibrated discharge coefficient was found to be 0.79 . Although this value is higher than normally considered for sharp-edged orifices, potential flow theory as explained in Olson and Wright (1990) indicates that larger $C_{D}$ values are expected when the width of the approach flow is not large with respect to the slot width. Here the width ratio is the pipe diameter to the slot width which is not large. 
Using the calibrated value for the discharge coefficient from the first five data points to predict the flow through the remaining length of the slot yields a relatively accurate result, as seen in Figure 21.10. The majority of the data points are well-predicted by the numerical model. The points with lower flow rates seem to be the least accurate and this can be described by the exaggerated surface tension effects of the film flow along the sides of the slot as discussed previously, as well as the breakdown in the onedimensional flow assumptions required for the application of Equations 21.2-21.4. Discharge measurement uncertainties are also greater with the low discharge experiments.

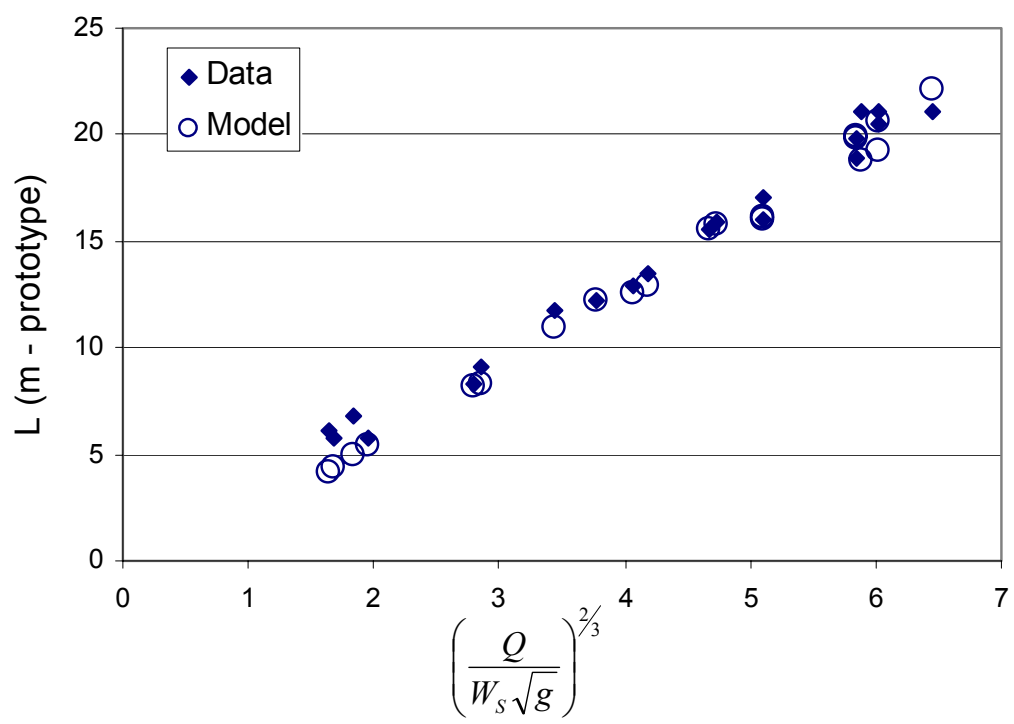

Figure 21.10 Numerical results vs. experimental data.

\subsection{Conclusions}

Some general statements can be made concerning the behavior of flow through this bottom outlet slot design.

- The vertical side walls beneath the discharge slot do not influence the discharge in any way that modifies either the 
upstream depth in the conduit or the length of slot filled by a particular flow. The reason for this is that the walls of the slot create a contraction of flow that prevents significant interaction with the vertical side walls.

- The Froude number characterizing the flow increased in the downstream direction. The transition from subcritical to supercritical flow occurs near the start of the slot opening.

- The flow patterns varied considerably in three dimensions, suggesting that an accurate numerical model describing the flow behavior may require more than the one-dimensional modeling framework proposed.

- A layer of film flow developed along the edge of the slot at the downstream end, increasing the length of slot through which water flowed. It is reasonable to assume that surface tension influences this film flow, lengthening the distance of flow along the slot edges. This phenomenon makes it difficult to precisely define the required slot length to pass a specified flow.

- Small adjustments to the conduit slope have a relatively minor influence on experimental results.

- The influence of changing the slot width can be well described by using the relationship:

$$
L=3.33 \cdot\left(\frac{Q}{W_{S} \sqrt{g}}\right)^{(2 / 3)}
$$

This slot length includes the film flow along the sides of the slot and can be reduced by approximately $10 \%$ and still capture all but a small fraction of a percent of the total discharge. With this consideration, the constant can be adjusted downward from 3.33 to approximately 3.00.

- Using the orifice assumption and the conservation of mass and energy principles as in an outlet diffuser, a relatively accurate numerical model can be used to predict the required slot length. 


\section{References}

Fischer, H.B., List, E.J., Koh, R.C.Y., Imberger, J., and Brooks, N.H. 1979. Mixing in Inland and Coastal Waters. Academic Press, pp. 412-416.

Henderson, F. M. 1966. Open Channel Flow. Prentice Hall. pp. 488-497.

Olson, R.M. and Wright, S.J. 1990. Essentials of Engineering Fluid Mechanics, Fifth Edition. Harper and Row. p. 236.

Warrick, A.W. and Yitayew, M. 1988. Trickle Lateral Hydraulics. I: Analytical Solution. J. Irrig. Drain. Eng., Vol. 114, (2) pp. 281-288.

Wu, I.P. and Gitlin, H.M. 1975. Energy Gradient Line for Drip Irrigation Laterals. J. Irrig. Drain. Eng., Vol. 101, (4) pp. 323-326.

Yitayew, M. and Warrick, A.W. 1987. Velocity Head Considerations for Trickle Laterals. J. Irrig. Drain. Eng., Vol. 113, (4) pp611-615.

Yitayew, M. and Warrick, A.W. 1988. Trickle Lateral Hydraulics. II: Design and Examples. J. Irrig. Drain. Eng., Vol. 114, (2) pp. 289-300. 
